\title{
D0I: https://dx.doi.org/10.21879/faeeba2358-0194.2021.v30.n63.p46-64 \\ OS BAILES AXIXAENSES COMO LUGARES EDUCATIVOS PARA MULHERES (DÉCADA DE 1960)
}

\author{
Delcineide Mํㅡㄹ Ferreira Segadilha* \\ Universidade Federal do Maranhão \\ https://orcid.org/0000-0002-9727-909X \\ Darlan Mélo** \\ Secretaria Municipal de Educação \\ https://orcid.org/0000-0002-4489-2130
}

\section{RESUMO}

Neste artigo, objetivou-se compreender em que medida bailes classificados como de Primeira e de Segunda funcionavam como lugares educativos para mulheres na sociedade de Axixá, Maranhão, da década de 1960. Ancorou-se na dimensão da História Cultural; metodologia da história oral. Realizou-se pesquisa bibliográfica e de campo. Usou-se entrevista semiestruturada com 6 (seis) pessoas idosas locais. Sustentou-se teoricamente em: Chartier (2002a, 2002 b, 2010) e Bourdieu (2007, 2012). Identificou-se, na sociedade axixaense da década de 1960, a existência de bailes classificados como de "Primeira" e de "Segunda", sendo para as mulheres rigidamente definido os que poderiam frequentar. Concluiu-se que os "Bailes de Primeira" e de "Segunda" funcionavam como lugares educativos para mulheres, na medida em que, por meio de sua dinâmica e práticas, educavam as mulheres sobre quais os seus lugares na sociedade local.

Palavras-chave: mulheres; bailes; representação; distinção.

\section{ABSTRACT}

\section{BAILES AXIXAENSES AS EDUCATIONAL PLACES FOR WOMEN (1960S)}

This article aimed to understand the extent to which dances classified as First and Second functioned as places of educational for women in the society of Axixá, Maranhão, in the 1960s. It was anchored in the dimension of Cultural History; methodology of oral history. Bibliographic and field research was carried out. Semi-structured interviews were used with 6 (six) local old people. It was theoretically supported in: Chartier (2002a, 2002b, 2010) and Bourdieu (2007, 2012). It was identified, in axixaense society of the 1960s, the existence of dances

* Doutora em Educação pela Universidade Federal do Rio Grande do Norte (UFRN). Professora Adjunto da Universidade Federal do Maranhão (UFMA). São Luís, Maranhão. Brasil. E-mail: delcineide.mf@hotmail.com

** Mestre em Gestão do Ensino da Educação Básica pela Universidade Federal do Maranhão (UFMA). Professor de História da Rede de Educação Básica da Secretaria Municipal de Educação/SEMED/SJR/MA. São Luís, Maranhão. Brasil. E-mail: dmelo9117@ gmail.com 
classified as "First" and "Second", being for women rigidly defined those who could attend. It was concluded that the "First and Foredances" and "Monday" functioned as educational places for women, since, through their dynamics and practices, they educated women about their places in local society.

Keywords: women; dances; representation; distinction.

\section{RESUMEN}

\section{BAILES AXIXAENSES COMO PLAZAS EDUCATIVAS PARA MUJERES (AÑOS 60)}

Este artículo tenía como objetivo entender hasta qué punto los bailes clasificados como Primera y Segunda funcionaban como lugares educativos para mujeres en la sociedad de Axixá, Maranhão, en la década de 1960. Estaba anclado en la dimensión de la Historia Cultural; metodología de la historia oral. Se llevó a cabo una investigación bibliográfica y de campo. Se utilizaron entrevistas semiestructuradas con 6 (seis) ancianos locales. Teóricamente se apoyó en: Chartier (2002a, 2002b, 2010) y Bourdieu (2007, 2012). Se identificó, en la sociedad axixaense de la década de 1960, la existencia de bailes clasificados como "Primero" y "Segundo", siendo para las mujeres rígidamente definidas las que podían asistir. Se concluyó que las "Primeras y Foredances" y "Lunes" funcionaban como lugares educativos para las mujeres, ya que, a través de sus dinámicas y prácticas, educaban a las mujeres sobre sus lugares en la sociedad local.

Palabras clave: mujeres; bailes; representación; distinción.

\section{Introdução}

O debate acerca da educação de mulheres tem se ampliado bastante nos últimos anos. Gradativamente, tem-se desvelado modos e maneiras de inculcação de modelos de educação para mulheres, desde os ambientes aparentemente mais inofensivos, como a família e a igreja, por exemplo. Mesmo chegando tardiamente às escolas, as mulheres desde muito cedo estiveram expostas a modelos educativos eficientes e duradouros. De modo sutil, concepções sobre como as mulheres devem se comportar na vida pública e/ou privada são internalizadas como naturais.

Estamos acostumados(as) a pensar processos educativos somente a partir da formação escolar, percebendo como "naturais" verdadeiros mecanismos educativos de disciplinarização de mentes e corpos. Contudo, os diversos processos de socialização a que sempre estivemos expostos, seja no âmbito da família ou socialmente, exerceram e exercem relevante persuasão na formação humana. As discussões de gênero, especialmente, têm colocado em evidência como mulheres e homens aprenderam/aprendem a definir as suas posições no mundo, inculcações que ocorrem em distintos âmbitos sociais. É nesse sentido que abordamos, neste artigo, histórias como as dos "Bailes de Primeira" e de "Segunda" do município de Axixá, Maranhão.

No município de Axixá, que dista aproximadamente $97 \mathrm{~km}$ da capital maranhense, São Luís, existiam na década de 1960 dois bailes classificados/denominados "Baile de Primeira" e "Baile de Segunda". A fim de situar o/a leitor(a) das dificuldades de acesso terrestre e de telecomunicações vivenciadas por esse município nessa década, ressaltamos que a estrada que conduzia até a capital era sedimentada por piçarra, e na época da estação chuvosa da 
região (janeiro a julho), essas estradas ficavam intrafegáveis devido à grande quantidade de lama, sendo as embarcações o meio de transporte mais utilizado nessa época. Os caminhos abertos pela areia branca no município eram chamados de rua pelos moradores de Axixá. 0 único meio de informação existente era o rádio, não havia telefone nem Correios.

Os/as antigos moradores(as), entrevistados(as) desta pesquisa, relataram que os bailes pesquisados possuíam destaque social, sendo a mulher um dos principais sujeitos diferenciadores deles, pois cada mulher deveria frequentar um local festivo específico, possuindo estes um padrão social, moral e, consequentemente, educativo. Dessa forma, esses bailes serviram como elementos sociadores, isto é, esses espaços festivos construíam efeitos recíprocos sobre os outros. Entretanto, no modo de sociação - formas ou modos como os indivíduos, atores sociais, se relacionam (SIMMEL, 2006), conceito ainda atual e sem edições mais recentes - dos bailes havia uma burla, a de que o sujeito masculino, frequentador do "Baile de Primeira", poderia frequentar também o "Baile de Segunda", no entanto, o sujeito masculino deste não poderia frequentar aquele baile. Assim, observamos que no "Baile de Segunda" existia certa liquidez na moral das pessoas que o frequentavam, possuindo um significado concreto na sociedade axixaense, características próprias da sociação, conforme definição de Simmel (2006, p. 60-61):

A sociação é, portanto, a forma (que se realiza de inúmeras maneiras distintas) na qual os indivíduos, em razão de seus interesses - sensoriais, ideais, momentâneos, duradouros, conscientes, inconscientes, movidos pela casualidade ou teleologicamente determinados -, se desenvolvem conjuntamente em direção a uma unidade no seio da qual esses interesses se realizam. Sejam eles sensoriais, ideais, momentâneos, duradouros, conscientes, inconscientes, casuais ou teleológicos, formam a base da sociedade humana.

Esses espaços festivos foram caracterizados nesta pesquisa por meio dos relatos de 05 (cinco) antigos(as) moradores(as) de Axixá que chegaram a frequentar esses bailes. De maneira lúcida, esses(as) moradores(as) dispuseram sons, vozes e cores dos referidos bailes. Diante dos relatos expostos, passamos à compreensão de como se deu a legitimação desses espaços festivos, da natureza de sua constituição.

Identificamos a relevância desta pesquisa na possibilidade de incentivo à produção acadêmica acerca da história das mulheres maranhenses, o que envolve lutas, preconceitos e representações, muito pouco investigados, conforme reitera Campos (2010, p. 39), em uma obra já com mais de 10 (dez) anos, mas sobre tal circunstância ainda vigente:

Mas ainda que as pesquisas sobre a temática (história das mulheres) no Brasil venham crescendo, alguns entraves, como a escassez e a fragmentação de documentos, a existência de um mercado editorial tímido para as publicações, a falta de debates sobre o tema e a concentração de pesquisas nas regiões sul-sudeste permanecem conservando lacunas em regiões como por exemplo, o Maranhão, onde as pesquisas históricas sobre as mulheres estão em fase inicial.

Diante do exposto, e agregando-se ao objeto de estudo, reafirmamos a riqueza que o campo de pesquisa da história das mulheres pode proporcionar à produção historiográfica, contribuindo para a compreensão de épocas passadas. Sobre o assunto, Tilly (2007, p. 34), em literatura clássica, comenta: "A história das mulheres certamente contribuiu para identificar e expandir nossa compreensão sobre novos fatos do passado, para incrementar nossos conhecimentos históricos." Nesse sentido, o campo da História das mulheres se insere no contexto historiográfico da humanidade como uma nova especialidade, devendo apoiar-se em especialidades mais antigas como a história econômica, política, social e as demais que compõem o complexo conjunto de domínios historiográficos.

A história da educação das mulheres vem sendo introduzida principalmente desde viragens da pesquisa histórica impulsionadas pelo movimento dos Annales, responsável pela introdução na pesquisa histórica de novas abor- 
dagens e novos objetos de estudo e pesquisa. Um processo de construção relevante para dar início a procedimentos de sensibilização no âmbito da produção historiográfica acerca da inclusão da ênfase ao protagonismo feminino nos estudos de diferentes contextos.

Como professores/pesquisadores da área da História, esse processo de construção de posturas investigativas acerca das mulheres na produção historiográfica sempre nos preocupou, no sentido de compreender como determinadas condições sociais das mulheres se construíram em contextos sociais e culturais não explorados, como na cidade de Axixá, Maranhão. Preocupação esta embasada nas dificuldades recorrentes de produção da história local, notadamente acerca de campos não visitados pela história tradicional, como a educação de mulheres.

Desse modo, a partir do conhecimento, durante a realização de pesquisas sobre a sociedade axixaense, da existência em décadas passadas, na cidade de Axixá, da realização de bailes classificatórios nos quais às mulheres era dispensado um tratamento extremamente diferenciado, cresceu nosso interesse em aprofundar a pesquisa pela história oral, visto que as fontes escritas sobre a temática são escassas, constituindo objeto dessa pesquisa: os bailes axixaenses da década de 1960 como lugares de educação para mulheres.

Assim, pensar a preocupação com a construção da história das mulheres em localidades como Axixá exigiria a compreensão de como essa preocupação se insere no contexto local. Nesse direcionamento, esboçar posturas de pesquisa sobre a história das mulheres em Axixá por meio da análise dos bailes axixaenses da década de 1960 envolve compreensões sobre: 1) a luta das mulheres na história; 2) a dinâmica dos bailes axixaenses da década de 1960; 3) o lugar da moral católica no contexto das representações dos bailes em Axixá; 4) e a inclusão/exclusão da mulher nos bailes de Axixá como prática educativa. Logo, elencamos como questões norteadoras desta pesquisa:
Quais alguns dos elementos da luta das mulheres pela conquista de visibilidade significativa em seu percurso histórico? Qual a dinâmica dos "Bailes de Primeira" e de Segunda" realizados em Axixá, na década de 1960? Qual o lugar do catolicismo na cimentação das concepções sobre os comportamentos sociais no contexto das festas realizadas em Axixá? Qual o lugar dos bailes de "Primeira" e de "Segunda" na educação das mulheres axixaenses da década de 1960?

Definidos objeto e questões norteadoras da pesquisa, passamos a delinear o nosso objetivo geral, que consiste em: compreender em que medida bailes classificados como de Primeira e de Segunda funcionavam como lugares educativos para mulheres na sociedade de Axixá, Maranhão, da década de 1960. Isto para responder ao problema: em que medida bailes axixaenses conhecidos como "Bailes de Primeira" e "Bailes de Segunda", década de 1960, funcionaram como lugares educativos para mulheres? Logo, tivemos como objetivos específicos: 1) discorrer sobre alguns dos elementos significativos da luta das mulheres por igualdade de gênero; 2) conhecer a dinâmica dos "Baile de Primeira" e "Baile de Segunda" realizados em Axixá na década de 1960; 3) identificar a presença da Igreja Católica no contexto de realização das festas em Axixá, década de 1960; e 4) relacionar as características dos "Bailes de Primeira" e de "Segunda" no contexto de uma educação para mulheres.

Delimitados os objetivos, passamos a explicitar o percurso metodológico. Como abordagem teórico-metodológica apoiamo-nos na História Cultural, ao passo em que trabalhamos com representações e apropriações mediadas por artefatos culturais como os bailes que ocorriam em Axixá. Tendo abordagem qualitativa, fizemos uso nesta pesquisa do método histórico, por permitir lidar com situações passadas relacionando-as a construções sociais vigentes.

Quanto à tipologia, classificamos esta pesquisa como histórica e de campo. Histórica, ao passo em que se trata de um estudo que investiga eventos já ocorridos em uma perspectiva descritiva e analítica; de campo, por realizar 
aproximação com pessoas-alvo da investigação para recolha de dados no local. Na qualidade de referencial teórico, nos sustentamos, majoritariamente, em Chartier (2002a, 2002b, 2010) e Bourdieu (2007, 2012), dos quais elegemos como categorias de análises: representações e distinção. Consequentemente, compreendemos representações como "esquemas intelectuais incorporados que criam as figuras graças às quais o presente pode adquirir sentido, o outro tornar-se inteligível e o espaço ser decifrado" (CHARTIER, 2002a, p. 17). Ou seja, concepções mentais de organização do real, orientadoras das práticas, classificadoras e hierarquizadoras desse mesmo real, práticas culturais a dirigir ações e instituir comportamentos. E distinção como a ação de distinguir, de fazer diferença.

Relevante também informar que utilizamos os termos educativos e educacionais, sendo o primeiro referente a qualquer lugar que eduque individual e coletivamente as pessoas, de modo intencional ou não; quanto a educacionais, referimo-nos à escola como lugar formal de educação de pessoas.

Relativamente aos instrumentos de investigação, usamos entrevistas semiestruturadas. Como sujeitos, entrevistamos 06 (seis) pessoas que tiveram como critério de escolha ser pessoa idosa, que vivenciou o período em estudo, com conhecimento significativo sobre a história da cidade. Os mesmos são apresentados na pesquisa com nomes fictícios e idade real. São eles: João, 81 anos; Pedro, 83 anos; Maria, 81 anos; Marizé, 90 anos; Cezino, 90 anos; e Lôla, 85 anos. 0 relato desses sujeitos trouxe uma diversidade de informações muito pertinente à compreensão das relações sociais em Axixá no período em estudo.

Para a entrevista ${ }^{1}$ elaboramos 06 (seis) perguntas iguais sobre os dois bailes, com os seguintes teores: origem e local de realização; organizadores(as); frequentadores(as); períodos (meses) de realização; funcionamento dos bailes; representações da sociedade sobre

1 As entrevistas foram realizadas mediante assinatura de Termo de Consentimento Livre e Esclarecido. esses bailes. Consequentemente, por se tratar de entrevistas semiestruturadas, perguntas adicionais foram feitas a fim de complementar nosso roteiro.

Bem sabemos o quanto a lembrança é falha e duvidosa, contudo, tomados os cuidados exigidos na pesquisa, é possível conseguir um material histórico consistente e rico para a compreensão de contextos remotos. Assim, escolhemos cinco pessoas contemporâneas e fomos triangulando as informações de cada um, visto que as entrevistas foram realizadas individualmente. Segundo Bosi (1994, p. 83), utilizada aqui por considerar-se um clássico:

As lembranças de velhos aparecem e nos surpreendem pela sua riqueza. 0 velho, de um lado, busca a confirmação do que se passou com seus coetâneos, em testemunhos escritos ou orais investiga, pesquisa, confronta esse tesouro de que é guardião. De outro lado, recupera o tempo que correu e aquelas coisas que, quando as perdemos, nos fazem sentir diminuir e morrer.

A triangulação das informações entre os/as entrevistados(as) foi um critério de pesquisa estabelecido pelos(as) autores(as), ao passo em que nos inclinamos mais ao que poderíamos considerar memória coletiva, visto que a memória individual se encaminha mais aos interesses de cada indivíduo. Sobre a memória coletiva, Halbwachs (1990, p. 47), referência ímpar no assunto, esclarece:

Não estamos ainda habituados a falar da memória de um grupo, mesmo por metáfora. Parece que uma tal faculdade não possa existir e durar a não ser na medida em que está ligada a um corpo ou a um cérebro individual. Admitamos, todavia, que haja, para as lembranças, duas maneiras de se organizar e que possam ora se agrupar em torno de uma pessoa definida, que as considere de seu ponto de vista, ora distribuir-se no interior de uma sociedade grande ou pequena, de que elas são outras tantas imagens parciais. Haveria então memórias individuais e, se o quisermos, memórias coletivas.

Em vista disso, esta pesquisa está ancorada na dimensão da História Cultural; abordagem da história oral; domínio dos estudos de gê- 
nero; e temática da educação de mulheres. A abordagem metodológica da história oral foi escolhida por considerarmos permitir a compreensão do contexto social axixaense no que se refere à condição das mulheres, a partir da análise de bailes realizados em Axixá, década de 1960. Nesse sentido, os relatos dos(as) sujeitos entrevistados(as) constituíram as fontes que nos deram pistas sobre as posições das mulheres no contexto da década de 1960 em Axixá. 0 nosso entendimento sobre a metodologia da história oral se coaduna com definição de Ferreira (2011, p. 170), em obra de referência ao campo historiográfico, ao argumentar que:

Em nosso entender, a história oral, como todas as metodologias, apenas estabelece e ordena procedimentos de trabalho - tais como os diversos tipos de entrevista e as implicações de cada um deles para a pesquisa, as várias possibilidades de transcrição de depoimentos, suas vantagens e desvantagens, as diferentes maneiras de o historiador relacionar-se com seus entrevistados e as influências disso sobre o seu trabalho -, funcionando como ponte entre teoria e prática.

A história oral constitui uma metodologia que dá um sentido de democratização à pesquisa, pela importância que os relatos orais adquirem, na medida em que dá visibilidade a sujeitos e temas antes excluídos pelo paradigma tradicional de ciência. Para François (2006, p. 4), "a história oral seria inovadora primeiramente por seus objetos, pois dá atenção especial aos 'dominados', aos silenciados e aos excluídos da história (mulheres, proletários, marginais etc.), à história do cotidiano". Constitui um campo a explorar a história da vida privada assim como a história local, ou seja, segmentos antes não vislumbrados na escrita da história, representando uma abertura de estudos e, logo, uma difusão de perspectivas sobre a compreensão das relações humanas e assim das possibilidades de (des)construções relevantes a envolver o preconceito, a discriminação, a superioridade de raças e gênero, tão cruéis para o desenvolvimento humano ainda na contemporaneidade.
A memória funcionou como fonte para esta pesquisa. Segundo Chartier (2010, p. 23), “[...] o testemunho da memória é o fiador da existência de um passado que foi e não é mais". Destarte, a lembrança dos(as) entrevistados(as) merece atenção especial em razão da idade deles(as), que, ocasionalmente, esqueciam informações relevantes, mas relembravam em momentos fora da entrevista. Sobre as suas experiências com memória de velhos, Bosi (1994, p. 39) comenta: "[...] as mais vivas recordações afloravam depois da entrevista, na hora do cafezinho, na escada, no jardim, ou na despedida no portão". Nesse sentido, a entrevista precisa ser conduzida com delicadeza para que a narração possa fluir normalmente, sem que haja a obstrução da memória dos(as) entrevistados(as).

De posse do depoimento dos(as) entrevistados(as), fizemos recortes de informações importantes para a pesquisa, como: os tipos sociais das mulheres que frequentavam tais espaços, montagem social do espaço festivo e a sua dinâmica.

Quanto à análise dos dados, realizamos leitura minuciosa das informações recolhidas e posterior interpretação delas, relacionando-as aos autores(as) e teóricos pertinentes.

\section{Mulheres: alguns elementos de uma luta}

Durante muito tempo, as mulheres não tiveram lugar na produção historiográfica, pois o paradigma tradicional da história enfatizava a política e os feitos dos "grandes" homens. Por conta da busca por novas perspectivas na escrita da história, observamos ao longo do século XX debates sobre novas abordagens, novos problemas e novos objetos no campo da produção historiográfica. Esses debates foram uma reação ao paradigma tradicional de se fazer a História, sendo considerado como marco dessas discussões a fundação da Revista Annales pelos historiadores Lucien Febvre, March Bloch e, depois, Fernand Braudel, que 
expandiu o debate sobre os novos horizontes da pesquisa histórica. Como preliminarmente mencionado, tais mudanças contemplaram temáticas antes excluídas da historiografia tradicional, a exemplo da história das mulheres (BURKE, 1992).

No âmbito da história das mulheres, o debate sobre esse território específico de estudo continuou, e se percebeu a existência de equívocos acerca da compreensão do objeto de estudo mulheres. Verificou-se, por exemplo, que as pesquisas sobre o elemento feminino deveriam ser percebidas de diversos ângulos, conforme a sociedade em que elas estivessem inseridas. É interessante pensar que os estudos sobre as mulheres nasceram a partir de uma circunstância comum a todas as mulheres, a saber, a dominação masculina construída dentro de relações diversas de poder. Contudo, essas discussões se expandiram sem considerar a existência das diferentes mulheres presentes em variados contextos sociais: a mulher negra, indígena, jovem, idosa, analfabeta, intelectual, oriental, ocidental, enfim, mulheres diversas, para além unicamente de uma categoria biológica. Nessa perspectiva, Tilly (2007, p. 31) reitera:

Ainda que definidas pelo sexo, as mulheres são algo mais do que uma categoria biológica; elas existem socialmente e compreendem pessoas do sexo feminino de diferentes idades, de diferentes situações familiares, pertencentes a diferentes classes sociais, nações e comunidades, em um meio no qual se configuram crenças e opiniões decorrentes de estruturas de poder.

Com os constantes debates ao longo dos anos sobre a história das mulheres, convencionou-se adotar o termo estudos de gênero, sendo este termo adequado também para se compreender melhor a significação social das mulheres nos diferentes tempos. Isso implica dizer que os termos masculino e feminino exigem uma análise de como a sociedade de uma determinada época compreende esses papéis sexuais, conforme explica Pinsky (2010, p. 31, grifo do autor): “Gênero trata da construção social da diferença sexual. Quando adotamos a perspectiva de gênero, estamos pensando nas maneiras como as sociedades entendem, por exemplo, o que é 'ser homem' e 'ser mulher', e o que é que consideram 'masculino' e 'feminino'.'

A luta de mulheres por visibilidade histórica se fez sentir em diferentes momentos do cenário social mundial, entretanto, um momento representativo desse histórico foi o que ficou conhecido como "Segunda Onda" do movimento feminista. Um período desse movimento no qual as mulheres ampliaram demandas, saindo do que se poderia considerar um feminismo único para múltiplos feminismos, viabilizando o aparecimento de distintas correntes teóricas, obedecendo, segundo Pinto (2010, p. 10), os seguintes moldes:

Na Europa e nos Estados Unidos, o movimento feminista surge com toda a força, e as mulheres pela primeira vez falam diretamente sobre a questão das relações de poder entre homens e mulheres. 0 feminismo aparece como um movimento libertário, que não quer só espaço para a mulher - no trabalho, na vida pública, na educação -, mas que luta, sim, por uma nova forma de relacionamento entre homens e mulheres, em que esta última tenha liberdade e autonomia para decidir sobre sua vida e seu corpo. Aponta, e isto é o que há de mais original no movimento, que existe uma outra forma de dominação - além da clássica dominação de classe -, a dominação do homem sobre a mulher - e que uma não pode ser representada pela outra, já que cada uma tem suas características próprias.

Quanto à "Terceira Onda" do movimento feminista, teve início, mais ou menos, pelos anos de 1990, tendo seu foco no combate às diversas formas de violência contra as mulheres, a exemplo da violência física e psicológica. Contudo, mesmo que se tenha avançado no que se refere à criação de leis e instituições de proteção às mulheres, os crimes contra elas ainda crescem a olhos vistos. Os casos de feminicídios, na atualidade, apresentam estatística assustadora, fruto da internalização de uma cultura machista que reforça a ideia da mulher enquanto propriedade masculina. No Brasil, a Lei Maria da Penha, sancionada em 07 de 
agosto de 2006, Lei no 11.340 (BRASIL, 2006), objetiva proteger a mulher da violência doméstica e familiar. Todavia, ainda não se constitui definitivamente efetiva na luta pela punição dos agressores, exigindo maior engajamento de variados grupos sociais nos embates.

Infelizmente, mais enfaticamente nos países em desenvolvimento, países mulçumanos e africanos, as mulheres ainda vivem na dependência dos homens, sob um regime patriarcal grotesco, uma situação que preocupa, mas que não diminui a luta pela igualdade de gênero e, consequentemente, pelo respeito mútuo.

Não obstante, as pesquisas realizadas sobre as mulheres em História contribuem sobremaneira para a compreensão relativamente ao papel desempenhado por elas nos diversos meios sociais, a fim de percebê-las não apenas na posição de vítimas, mas também de vilãs, de transgressoras, de não submissas à figura masculina, bem como outro papel social diverso que lhe era disposto. Assim, nos últimos anos, têm sido dinâmicos os estudos sobre o papel das mulheres na história, muito especialmente no âmbito acadêmico. As pesquisas de diferentes grupos de estudos têm avançado no que se refere às variadas possibilidades de se estudar as mulheres nos espaços humanos, enfatizando o desenvolvimento dessa luta.

\section{Os tempos inesquecíveis dos bailes opostos}

As mulheres, em Axixá, apesar de iguais biologicamente, eram direcionadas para distintos espaços festivos axixaenses, conforme sua adequação ao padrão moral socialmente aceito naquela época e local. Assim, as mulheres aceitas por certo padrão moral imposto eram direcionadas para o "Baile de Primeira", e as que não se "enquadravam" nesse padrão eram conduzidas para o "Baile de Segunda". Eram chamados "Bailes de Primeira" as festas frequentadas pelas moças e mães consideradas "de família", "honradas"; e "Bailes de Segunda" as festas frequentadas por mulheres "mal faladas" e homens "brigões", "arruaceiros", consequentemente pessoas, em sua maioria, de condição social mais humilde.

No início da entrevista com cada um(a) dos(as) participantes da pesquisa, perguntamos sobre a origem dos "Bailes de Primeira" e de "Segunda". Nenhum dos entrevistados soube dizer quando se deu o início dos referidos bailes. Eles disseram que quando souberam da existência dos bailes, isso por volta dos 10 anos de idade, essas festas já aconteciam há muito tempo. Observamos, portanto, que eram festas que ocorriam tradicionalmente, sem que houvesse preocupação com seu início, contudo, as lembranças e representações permaneceram.

Nas entrevistas realizadas foi relatado que os "Bailes de Primeira" e de "Segunda" eram realizados na mesma localidade e dia, porém distantes geograficamente. Tais bailes ocorriam ao som de instrumentos musicais (sopro, cordas e percussão), e eram realizados no período carnavalesco ou em festejos de santos católicos em seus respectivos meses: Nossa Senhora da Luz (setembro), Nossa Senhora de Santana (julho), Santo Antônio (junho) e Nossa Senhora da Saúde (novembro).

De acordo com os/as entrevistados(as), o "Baile de Primeira", frequentado apenas por famílias e moças consideradas "honradas", geralmente acontecia em prédios públicos como escolas ou prédios da prefeitura, tinha representação de um ambiente de respeito e ordem (JOÃO; PEDRO; MARIA; MARIZÉ). ${ }^{2}$ Quanto ao "Baile de Segunda", era considerado o oposto do primeiro, sendo visto com desprezo por boa parte das pessoas ditas de "bem", possuía representação de lugares frequentados por "mulheres mal faladas", das "camaradas" (como eram chamadas as amantes, mulheres que mantinham relacionamento amoroso com homens casados), dos "brigões" e "beberrões" (JOÃO; PEDRO). ${ }^{3}$

2 Entrevistas realizadas nas seguintes datas: João, 28 de dezembro de 2018; Pedro, 03 de janeiro de 2019; Maria, 04 de janeiro de 2019; Marizé, 05 de janeiro de 2019.

3 Entrevistas realizadas nas seguintes datas: João, 28 de dezembro de 2018; Pedro, 03 de janeiro de 2019. 
Os "Baile de Primeira" e de "Segunda" possuíam uma dinâmica que definia sua caracterização. Os primeiros eram considerados ambientes de respeito e ordem. Os segundos eram vistos com discriminação pelas "pessoas de bem". Esse universo das representações é a forma de inteligibilidade sobre como as pessoas viam esses espaços, e através dessas representações os indivíduos acomodavam coisas, espaços e pessoas aceitos por eles, excluindo aqueles que não lhes agradavam. Uma lógica na qual os bailes eram lugares construídos e mantidos a partir de um processo intersubjetivo no qual os indivíduos construíam imagens de si e dos outros. Sobre tal processo, Chartier (2002b, p. 35) explica que “[...] a representação desses espaços determina posições e relações que constroem, para cada classe, grupo ou meio, um ser percebido constitutivo de sua identidade". Esse autor corrobora essa afirmação quando esclarece que essas representações servem de elemento coesivo da sociedade em que o indivíduo está inserido, em um mecanismo no qual "[...] as formas institucionalizadas e objetivadas, [...] marcam de modo visível e perpétuo a existência do grupo, da comunidade ou da classe" (CHARTIER, 2002b, p. 35). A construção da identidade percorre caminhos mediados pelas representações: o produto de uma relação de forças entre as representações impostas e a definição submetida ou resistente que cada comunidade produz de si mesma; assim como pelo crédito que se concede à representação que cada grupo faz de si mesmo (CHARTIER, 2002b).

No "Baile de Primeira", as moças de família iam em companhia de seus pais e/ou irmãos. Maria lembrou da formalidade para se frequentar o "Baile de Primeira", explicou que para ir a esses bailes havia necessidade do recebimento de um convite escrito da parte de seus promotores ao chefe de cada família. Comentou que o seu pai costumava receber esses convites. Esses bailes possuíam regras a serem seguidas pelas moças que os frequentavam, regras como a de que as moças solteiras só podiam dançar de rosto "colado" se fossem noivas de seus namorados, assim como essas moças não poderiam sair do baile desacompanhadas dos membros da sua família. Caso isso acontecesse, não seria mais permitida a entrada da moça no ambiente festivo (JOÃO; PEDRO; MARIA; MARIZÉ; CEZINO) ${ }^{4}$. Maria ainda acrescentou que ninguém soube que isso tivesse ocorrido com alguma moça, uma vez que elas temiam o que as pessoas podiam falar e a punição física dada pelo pai. Explicou também que o local da festa era iluminado por vários lampiões para maior controle de todas(os).

Pelos relatos, observamos a existência de uma moral repressora instituída, definidora de posicionamentos sociais responsáveis pela manutenção das relações sociais da época, uma ação educativa. Verdadeiramente, os bailes funcionavam como mecanismos outros de disciplinarização dos corpos, formadores de pessoas dóceis, disciplinadas, prontas para aceitar. Tal engendro se explica bem na advertência de Foucault, (2010), que considera a disciplina um método de poder que consiste em uma vigilância perpétua e perene das pessoas. Consta da construção de uma pirâmide contínua de olhares. "É assim que no exército aparecem sistemas de graus que vão, sem interrupção, do general chefe até o ínfimo soldado, como também os sistemas de inspeção, revistas, paradas, desfiles, etc., que permitem que cada indivíduo seja observado permanentemente." (FOUCAULT, 2010, p. 106).

Relativamente aos "Bailes de Segunda", os/ as entrevistados(os) relataram que este baile era realizado em um terreno descampado pertencente ao dono da principal quitanda da cidade, terreno que se localizava em frente à casa do referido comerciante. Esse terreno era contornado por uma cerca feita das folhas da palmeira de babaçu, formando uma espécie de arraial junino, tendo à entrada do arraial um porteiro, a fim de cobrar o valor da entrada aos

4 Entrevistas realizadas nas seguintes datas: João, 28 de dezembro de 2018; Pedro, 03 de janeiro de 2019; Maria, 04 de janeiro de 2019; Marizé, 05 de janeiro de 2019; Cezino, 06 de janeiro de 2019. 
homens, pois mulheres não pagavam o acesso ao baile. 0 ambiente era envolvido em penumbra, já que a visibilidade do local era diminuta, devido à existência de apenas 4 lampiões de gás para iluminar o terreno disposto para o baile ao ar livre, bem diferente do ambiente dos "Bailes de Primeira" (JOÃO; PEDRO; CEZINO). ${ }^{5}$

Os "Bailes de Segunda" eram frequentados por "mães solteiras" e "aventureiras solteiras", sendo embalado ao som de instrumentos de sopro, rabeca, bumba e pandeiro. Nesse ambiente festivo ocorriam muitas brigas e geralmente alguém "saía furado de faca", episódio que levava ao encerramento da festa. Relevante relembrar que os homens frequentadores dos "Bailes de Primeira" podiam frequentar os "Bailes de Segunda" (LÔLA; CEZINO). ${ }^{6}$

São relatos que nos permitem perceber o "crivo" social sob o qual o indivíduo seleciona o que está a sua volta. Constitui uma relação de consentimento, dependência e dominação, uma racionalidade instituída pela lógica da distinção pela dependência. Sobre essa relação de dominação, dependência e consentimento, Chartier (2002a, p. 112) adverte que pelo uso da "etiqueta, a sociedade de corte procede a autorrepresentação, cada um distinguindo-se do outro, e distinguem-se todos em conjunto das pessoas estranhas ao grupo". Por conseguinte, o poder do disciplinamento das classes consideradas inferiores se estabelece como forma de atuação e reprodução social da parte dos setores dominantes, é claro, com o próprio consentimento daquelas - dominados(as) -, na medida em que nesse conjunto tanto se repelem quanto se atraem. É nesse sentido que mecanismos como esses bailes, marcadamente excludentes, se sustentaram por tanto tempo na sociedade axixaense, suprimindo interesses dos menos favorecidos e perpetuando as assimetrias sociais, em um processo de rigorosa educação pelas práticas.

5 Entrevistas realizadas nas seguintes datas: João, 28 de dezembro de 2018; Pedro, 03 de janeiro de 2019; Cezino, 06 de janeiro de 2019.

6 Entrevistas realizadas nas seguintes datas: Lôla, 08 de janeiro de 2019; Cezino, 06 de janeiro de 2019.

\section{No embalo da moral católica}

Na década de 1960, a moral católica predominava no município de Axixá, visto que a maioria dos habitantes se declarava católica. Constatamos pelos relatos que essa moral predominante era mais exigida dos indivíduos mais abastados e dos agregados destes. Maria, João e Pedro relataram que eram afilhados do anfitrião do "Baile de Primeira", senhor muito respeitado na região, detentor de muitas posses, e o principal mantenedor da igreja católica local. As posses desse anfitrião vinham do lucro obtido pela venda do óleo extraído da amêndoa da andiroba, matéria-prima usada para a fabricação do sabão de andiroba, produto super valorizado na época. Os pais desses(as) entrevistados(as) eram pescadores, mas estabeleceram uma amizade de compadrio com esse senhor, o que solidificou a relação "amistosa" entre eles.

A presença da figura do padrinho e da madrinha se fizeram constantes ao longo da história brasileira, em que os/as apadrinhados(as) eram incorporadas(as), por "afinidade", à vida familiar dos padrinhos. Conforme Florentino e Góes (1997, p. 91-92), os laços de compadrio constituem relações parentais ancoradas na espiritualidade, contudo, tão relevantes quanto "aquelas de outros tipos, como as de base consanguínea ou o parentesco por meio de alianças matrimoniais, sobretudo no âmbito de uma sociedade em que o cristianismo a tudo plasma". Estas eram relações comuns no Brasil desde o período colonial, tendo atravessado gerações, perpetuando a convivência aparentemente "harmoniosa" no que se relaciona aos interesses distintos das partes envolvidas nesses laços sociais.

Um dos principais mecanismos de estabelecimento dessas relações era o batismo, instrumento que permitia a manutenção de relações de parentesco entre pessoas de classes sociais diferentes, porém, sem ameaçar o patrimônio dos mais abastados, visto que os/ as afilhados(as) não se constituiriam herdei- 
ros. De sua parte, as pessoas pertencentes às classes sociais subalternas passavam a contar com a manutenção de sua cultura e algum tipo de proteção da parte das classes sociais mais elevadas (BRÜGGER, 2007).

Na verdade, essas relações terminavam por esconder um amálgama de interesses e conflitos diversos, mas que constituíam mecanismos de relevantes distinções sociais que demarcavam a posição de cada um/uma no contexto social vigente, a exemplo da posição feminina, ou melhor, das posições, visto que as mulheres recebiam tratamento diferenciado a partir da sua condição social. Esse artifício se tornou patente em Axixá com a classificação dos bailes, claramente definidos por categorias sociais: "Bailes de Primeira" e "Bailes de Segunda". Todos tinham direito ao lazer, no entanto, respeitando-se as diferenças morais e sociais, em uma relação de consentimento, na qual a etiqueta local definia os lugares sociais, disciplinava.

0 "Baile de Primeira" era o ambiente de pessoas "distintas", moral e socialmente, conforme a fé cristã católica. Dessa forma, ser agregado, no sentido de ter uma relação de amizade sólida com os mais abastados, era coadunar com as mesmas pretensões de moral e de sociedade destes. Compreendemos nessa assertiva que o agregado internalizava afetuosamente o ser percebido pela existência do compadre, sendo que este se apropriava da razão de ser daquele em sua causa e finalidade. Sobre essa relação "afetuosa", concretizada em questões de gostos comuns, Bourdieu (2007, p. 228.) informa que "a melhor prova de afinidade de gostos entre duas pessoas é a afeição que sentem uma pela outra". E era/é justamente esse sentimento de afeição que cimentava/cimenta essas relações assimétricas entre diferentes grupos sociais, camuflando as distinções. Contudo, especialmente em relação às mulheres não pertencentes aos setores sociais mais abastados, essas diferenças são explicitamente demarcadas, em um processo de despolitização do político pela prática religiosa. De acordo com Bourdieu (2007, p. 402):
Antes de mostrar espanto diante da intensidade da correlação constatada entre a prática religiosa e a opinião política, convém se interrogar se ela se deve, em grande parte, ao fato de que se trata apenas de duas manifestações diferentes da mesma disposição; não só porque, tanto em seu conteúdo quanto nas disciplinas de inculcação a formação religiosa é uma forma eufemizada de socialização política, mas também porque a imposição de uma prática e de uma crença declarada implica a afetação a uma classe, portanto, a atribuição de uma identidade social que, seja qual for o conteúdo da inculcação correspondente, encontra-se definida relacionalmente por sua oposição à classe complementar dos 'não crentes' e, assim, encontra-se carregada com todas as propriedades excluídas, em determinado momento, dessa última classe.

A manutenção dos dois lugares festivos deveria ser observada nos meses de festejos dos santos católicos ou no carnaval. Tal manutenção era compreensível, na medida em que era de interesse da moral católica. No entanto, nos chama atenção a manutenção desses espaços festivos diferenciados em Axixá no período carnavalesco, pois até mesmo em plena Idade Média as possíveis barreiras sociais existentes entre os indivíduos eram diminuídas nesse período. Sobre o assunto, Bakhtin (1993) revela que a supressão das relações hierárquicas na Idade Média continha sentido incomum. Nas festas oficiais, as distinções hierárquicas tinham destaque intencional, "cada personagem apresentava-se com as insígnias dos seus títulos, graus e funções e ocupava o lugar reservado para o seu nível" (BAKHTIN, 1993, p. 9). Eram festas que tinham por finalidade a consagração da desigualdade, ao contrário do carnaval, no qual "todos eram iguais e onde reinava uma forma especial de contato livre e familiar entre indivíduos normalmente separados na vida cotidiana pelas barreiras intransponíveis da sua condição, sua fortuna, seu emprego, idade e situação familiar" (BAKHTIN, 1993, p. 9). Tal enredo nos permitiu constatar que o poder moral católico era intensamente arraigado na sociedade axixaense da década de 1960, e como valor cultural impregnava a 
maioria dos setores da sociedade, inclusive os ambientes festivos, embora houvesse um lugar que transgredia esse padrão moralizante, o "Baile de Segunda."

\section{0 poder de escolha do homem de "primeira"}

0 poder de escolha da mulher acerca do baile que gostaria de frequentar ficava muito aquém se comparado ao do homem, especialmente daquele frequentador do "Baile de Primeira", que possuía o privilégio de escolher frequentar os dois bailes. Quanto ao homem frequentador do "Baile de Segunda", era permitido somente frequentar este último, uma clara relação de distinção e discriminação social. Sobre o mecanismo da distinção, Bourdieu (2007, p. 67) explica que a compreensão desse processo pressupõe não identificar a circulação de modelos culturais como uma imposição direta, mas compreendê-la como resultado de uma tensão a ser reproduzida sempre no processo de constituição da distinção pela diferença, "apropriação pela imitação social ou pela imposição aculturante". Essa é uma análise proposta para todas as formações sociais, entretanto, Chartier (2002a, 2002b) adverte sobre o mecanismo da interpretação que pode conduzir às estratégias e táticas bem evidenciadas por Certeau (2008), em A invenção do quotidiano: artes de fazer. Ainda sobre a constituição da distinção, Bourdieu (2007, p. 241) reitera:

[...] a classe dominante constitui um espaço relativamente autônomo, cuja estrutura é definida pela distribuição, entre seus membros, das diferentes espécies de capital, de modo que cada fração é caracterizada propriamente falando por certa configuração dessa distribuição à qual corresponde, por intermédio dos habitus, certo estilo de vida; se é verdade que a distribuição do capital econômico e a distribuição do capital cultural, entre as frações, apresentam estruturas simétricas e inversas, e que as diferentes estruturas patrimoniais estão, com a trajetória social, no princípio do habitus e das escolhas sistemáticas que ele produz em todos as do- mínios da prática e cujas escolhas, comumente reconhecidas como estéticas, constituem uma dimensão, deve-se reencontrar essas estruturas no espaço dos estilos de vida, ou seja, nos diferentes sistemas de propriedades em que se exprimem os diferentes sistemas de disposições.

0 lazer de alguns homens frequentadores dos "Bailes de Primeira" era dividido em dois momentos, no que diz respeito à frequência aos bailes. 0 primeiro momento se dava com a ida ao "Baile de Primeira", sendo o cumprimento da obrigação do lazer junto com a família; porém, após o cumprimento da tal dever, muitos deles iam para o "Baile de Segunda", pois lá reinava a liberdade, a "desordem". Na verdade, esses homens possuíam o privilégio de participação nos dois espaços festivos classificados pelo capital econômico e relações de compadrio que definiam gostos e preferências. Para Chartier (2002a), estudar a história cultural de uma localidade pressupõe identificar a maneira como em diversos lugares e momentos uma dada realidade é construída, pensada, dada a ler, representada. Nesse sentido, apreender as representações que constroem as realidades envolve atentar às

[...] classificações, divisões e delimitações que organizam a apreensão do mundo social como categorias fundamentais de percepção e de apreciação do real. Variáveis, consoante as classes sociais ou os meios intelectuais, são produzidas pelas disposições estáveis e partilhadas, próprias do grupo. São estes esquemas intelectuais incorporados que criam as figuras graças as quais o presente pode adquirir sentido, o outro tornar-se inteligível e o espaço ser decifrado. (CHARTIER, 2002a, p. 17).

Sobre os dois momentos de frequência de alguns homens aos "Bailes de Primeira e de Segunda", Marizé relatou que o seu pai a deixava junto com a sua irmã em um "Baile de Primeira", ficando ambas sob a responsabilidade momentânea de um casal da confiança do pai, enquanto ele se dirigia para um "Baile de Segunda" acompanhado de sua "camarada", termo utilizado na época, naquela localidade, para designar amante. 
João, Pedro e Cezino, com idade aproximada de dezesseis anos à época, eram liberados pelos pais para frequentar o "Baile de Segunda" a fim de reafirmarem a sua independência masculina e a possibilidade de iniciar a sua vida sexual. Nesses bailes, João e Pedro disseram ter presenciado, muitas vezes, seu pai com as amantes, o que encaravam com naturalidade. Uma "naturalidade" herdeira das relações patriarcais que definiam muito bem o papel das mulheres em diferentes sociedades. Conforme Hanner (2013, p. 44):

[...] o pai e marido autoritário dominava seus filhos e filhas e sua esposa submissa, ao mesmo tempo que se cercava de concubinas ou se relacionava sexualmente com escravas. A esposa, por sua vez, era uma figura indolente e passiva, que pouco saía, dava à luz um grande número de filhos.

Acerca da dominação masculina, notadamente sobre as mulheres nas diferentes sociedades históricas, Del Priore (2005) caracteriza bem os polos distintos em que se encontravam homens e mulheres no que diz respeito às atitudes e sentimentos esperados por eles: dominação e obediência. Explica que "os maridos deviam mostrar-se dominadores, voluntariosos no exercício da vontade patriarcal, insensíveis e egoístas" (DEL PRIORE, 2005, p. 37). De sua parte, as mulheres deveriam apresentar-se como "fiéis, submissas, recolhidas. Sua tarefa mais importante era a procriação." Talvez as mulheres fossem simplesmente tratadas como máquinas de procriar, subjugadas a relações sexuais mecânicas e sem ternura" (DEL PRIORE, 2005, p. 37). Um modelo que bem explica a relação de dominação e poder masculino instituída sobre as mulheres em Axixá.

Ao homem do "Baile de Segunda" não cabia o poder de escolha sobre a frequência dos bailes, ao passo que à porta de entrada do recinto em que o "Baile de Primeira" estava se realizando um porteiro permitia a entrada apenas daquelas famílias comunicadas previamente pelo anfitrião da festa. Os homens frequentadores do "Baile de Segunda" eram caracterizados como "desordeiros", "beberrões”, "perigosos", e a presença deles à porta de entrada do "Baile de Primeira" era motivo suficiente para a aglomeração de homens no sentido de não lhes permitir entrar nesse espaço festivo (JOÃO; PEDRO; CEZINO).

A dinâmica dos "Bailes de Primeira" evidencia as diferenças de capital econômico e da distinção dos homens frequentadores dessas festas. Uma distinção em relação aos outros homens. Circunstância explicada por Bourdieu (2007), ao advertir que os julgamentos e preferências estéticos estão ligados à posição do indivíduo na sociedade, a um habitus de classe, e que será a diferença entre os habitus de classe, entre os estilos de vida que estão na base da distinção entre as classes sociais, e que são analisados a partir das práticas culturais e de consumos culturais. Para Bourdieu (2007), essa análise explicita toda violência simbólica, não perceptível como tal, inclusive pelas suas próprias vítimas, envolvidas na luta de classe contemporânea que está por trás da reprodução social.

Relativamente às mulheres, o comportamento dos homens dos "Bailes de Primeira" revela uma situação de insensibilidade e humilhação, na medida em que elas aceitavam de modo inquestionável as posturas e atitudes dos maridos. Conforme Bourdieu (2012, p. 71), as imposições contínuas, silenciosas e invisíveis que o mundo sexualmente hierarquizado dirige às mulheres as preparam, mediante explícitos apelos promotores da ordem, "a aceitar como evidentes, naturais e inquestionáveis prescrições e proscrições arbitrárias que, inscritas na ordem das coisas, imprimem-se invisivelmente na ordem dos corpos", definindo as posições das mulheres nos âmbitos familiar e social.

\section{Cada mulher em sua festa: classificações que educam}

A delimitação dos espaços femininos sempre foi algo presente nos diversos momentos 
da história da humanidade. Na Grécia antiga existia o gineceu, parte da casa grega destinada às esposas de cidadãos atenienses, onde as mães realizavam a educação das filhas, embora outros indivíduos pudessem transitá-lo. Conforme Santos (2010, p. 13):

\section{[...] o gineceu - o espaço feminino - um espaço restrito às mulheres e aos membros daquela família, os homens autorizados a entrarem neste espaço eram: o pai, o marido, o filho, o irmão, o tio. Todos ligados a mulher por laços de parentesco. Um homem de fora nunca entraria neste espaço.}

Aos poucos as mulheres foram adquirindo mais liberdade, podendo frequentar lugares variados, mas sempre à sombra das estruturas patriarcais. Contudo, embora a mulher brasileira, por exemplo, nos espaços representativos conquistados no âmbito do trabalho ainda enfrente múltiplos tipos de assédios, não se intimida frente às investidas sexuais e de desmoralização trabalhista sofridas (RAGO, 2013). Prossegue em uma luta incessante, conquistando outros espaços públicos (Ordem dos Advogados do Brasil e direito ao voto, por exemplo), apesar das objeções (SOIHET, 2013).

Em relação às festas no Brasil, Pereira (2002) relata que nos desfiles de rua do carnaval carioca do final do Império era costumeiro haver espaços diferenciados nessa festividade para o público feminino, explicitando um caráter de diferenciação social demarcado por um ideal de moralidade. Havia, então, o espaço destinado às mulheres "civilizadas", "exemplares" e de "boa família", e o espaço da rua destinado às mulheres que estavam fora desse requisito moral e social. Da pesquisa feita em jornais da época, esse autor observou que nos anúncios de bailes e desfiles havia alusão às mulheres e aos seus respectivos espaços nas festas carnavalescas:

Não é casual (nos jornais) que os pedidos sempre fossem dirigidos às distintas senhora, ou às belas fluminenses, enfim, às mulheres que assistiam aos desfiles do alto das sacadas dos sobrados ou das janelas. Este era um constante recurso discursivo para que as sociedades afirmassem seu caráter civilizado, delicado e distinto. Do mesmo modo que os chamados às filhas do pecado, às 'camélias' serviam para que os sócios se definissem como os licenciosos senhores da alegria nos seus bailes, a ocasião do desfile demandava um chamado às mulheres honestas e ricas - ou pelo menos que tivessem dinheiro ou posição social para assistir ao desfile 'protegidas' da multidão das ruas -, reafirmando por meio desse chamado, a missão pedagógica e civilizadora da qual se acreditavam imbuídos. (PEREIRA, 2002, p. 316).

Pereira (2002, p. 318) prossegue a sua análise sobre o carnaval carioca reafirmando os distintos espaços direcionados para os diferentes tipos de mulheres: "Os Tenentes do Diabo ofereciam um baile às "Vênus contemporâneas', definidas por eles como aquelas que não podem ser casadas, nem devem ficar solteiras." Explica que os lugares oferecidos a essas mulheres era contrário ao das senhoras fluminenses. Estas tinham lugar seguro de espectadoras, enquanto aquelas deveriam assumir lugar dinâmico na diversão. Desfilavam nos carros, chamavam sempre a atenção. "Na demarcação de lugares definidos pelos senhores da alegria, cada tipo de mulher, em seus respectivos lugares e função, servia, por sua vez, à demarcação das prerrogativas dos próprios senhores." (PEREIRA, 2002, p. 318). Os espaços carnavalescos do Rio de Janeiro eram demarcados socialmente para os diversos tipos de mulheres, embora estas nem percebessem o caráter de exclusão dessa festa popular. Neles também era adotado como elemento definidor o caráter moral e social de cada mulher, seja como participante ou como espectadora.

Similarmente às circunstâncias do Rio de Janeiro, em Axixá, na década de 1960, as posições morais e sociais eram definidas pela forma como as pessoas se inseriam socialmente, educando-se mutuamente, sendo tal demarcação estipulada por sua vinculação aos "Bailes de Primeira” ou de "Segunda." No decorrer das entrevistas, perguntamos aos/ às entrevistados(as) qual era o tipo de mulher moral e socialmente bem aceito na sociedade 
axixaense. A resposta foi unânime: moça que namorasse na frente dos pais, fosse bem comportada (pernas bem cruzadas, voz em tom ameno), andasse bem vestida (vestido ou saia ao meio do joelho) ou casada e cumpridora das tarefas do lar (JOÃO; PEDRO; MARIA; MARIZÉ; CEZINO; LÔLA).

Outra similaridade percebida à situação do Rio de Janeiro refere-se às mulheres frequentadoras do "Baile de Segunda", que geralmente eram mães solteiras, sendo os pais de seus filhos, na maioria das vezes, homens casados. Essas mulheres, por não possuírem união selada pelo "sagrado matrimônio", eram excluídas socialmente, consideradas "mal vistas", contudo, sempre mantinham o desejo de casar e constituir família. De outra parte, havia as mulheres solteiras, com ou sem filhos, que mantinham relações amorosas instáveis, em geral com homens casados, mas não possuíam o desejo de constituir família (LÔLA; MARIA).

A relação entre as mulheres (esposas e amantes, quietas e extrovertidas) era, segundo os/as entrevistados(as), considerada "tranquila”, uma vez que cada uma delas internalizava o seu papel social, e se faziam reclusas em seus espaços demarcados moral e socialmente. Segundo Sutil (2020, p. 130), "as mulheres estavam sujeitas à fraqueza, debilidade, languidez ou covardia de caráter, mas algo fraco, ou frágil, deveria ser preservado para não instigar a astúcia. Ser astuta implicava em atravessar a fronteira do equilíbrio."

A posição simbólica de cada mulher na sociedade axixaense, na década de 1960, revela as distinções advindas sobre os seus corpos e a manutenção de uma desigualdade social "consentida". Essas desigualdades eram externadas também nos momentos festivos, em que as mulheres despontavam como um dos principais elementos diferenciadores dos bailes existentes. Uma realidade que bem se explica pelas assertivas de Bourdieu (2007) em relação ao gosto. Para esse autor, o gosto opera a conversão das coisas em sinais distintos e distintivos, da divisão perene em assimetrias descontínuas; transforma a diferença física dos corpos em distinções significantes, simbólicas. Altera práticas classificadas em práticas classificadoras. 0 gosto se encontra no princípio do sistema de distinção no qual é percebido como expressão organizada de uma classe específica de condições de existência. A imposição de estilos distintivos de vida por aqueles(as) que possuem o conhecimento prático das relações entre os códigos distintivos e os lugares de distribuição entre os espaços objetivos de caráter científico e os estilos de vida existentes como únicos possíveis.

Cada mulher e cada baile estavam atrelados às diversas representações construídas na sociedade axixaense da década de 1960. Representações que permitem aos indivíduos pensar a sua relação com o mundo, instaurando classificações e divisões de ordenação dos espaços sociais, práticas culturais a dirigir ações e instituir comportamentos. Conforme Chartier (2002a), as representações do mundo social, ainda que almejem a universalidade de uma análise embasada na razão, são definidas pelos grupos que as constroem. Motivo pelo qual devemos dar atenção à relação entre os discursos e o lugar dos que os proferem e utilizam. As representações do social não são mensagens imparciais, "produzem estratégias e práticas (sociais, escolares, políticas) que tendem a impor uma autoridade à custa de outros, por elas menosprezados" (CHARTIER, 2002a, p. 17), que legitima projetos que busquem reformar ou justificar as escolhas e condutas dos indivíduos.

Daí porque Chartier (2002a) situe as representações em um campo de concorrências e competições, em uma relação de poder e dominação, ressaltando que as lutas das representações são tão importantes quanto as econômicas no sentido de se entender os métodos por meio dos quais um grupo se sobrepõe a outro, impondo os seus valores e o seu domínio, situação claramente vivenciada em Axixá no período em estudo. Tais condições podem ser vistas nas relações de compadrio 
e, especialmente, na classificação dos bailes axixaenses a relacionar gosto e poder.

Diante do exposto, constatamos que cada mulher relacionada ao seu respectivo baile constituía um significado universal pela sociedade axixaense daquela época, sendo esse significado legitimado por cada grupo que construiu socialmente os "Bailes de Primeira", os "Bailes de Segunda", e o ideal de mulher que pudesse frequentá-los. Assim, as mulheres em Axixá, não diferentemente de diversos outros lugares e espaços, contudo, respeitando-se as especificidades locais e de tempo, internalizavam em seu cotidiano os requisitos necessários para frequentar o tipo de baile adequado ao seu tipo moral e social, assumindo uma condição social de submissão naquela sociedade, submissão esta reforçada pelas circunstâncias religiosas e econômicas, demarcadas exclusões de gênero e social, um projeto educativo em movimento.

\section{Considerações finais}

As condições das mulheres ao longo da história da humanidade têm sido marcadas por estigmas que culminam na adoção de posturas que beiram a humilhação. 0 presente artigo se propôs compreender, a partir da análise da dinâmica de diferentes bailes realizados em Axixá, Maranhão, década de 1960, em que medida tais bailes se constituíram lugares educativos para mulheres.

Os bailes realizados na cidade de Axixá chamam atenção pela sua permanência na memória de idosos(as) que vivenciaram esses eventos a partir da década de 1960. Assim, apoiados nas narrativas de 06 (seis) idosos(as) residentes na referida cidade, a saber: João, 81 anos; Pedro, 83 anos; Maria, 81 anos; Marizé, 90 anos; Cezino, 90 anos; e Lôla, 85 anos, verificamos que as lembranças de velhos são surpreendentes e relevantes para a historiografia pela sua riqueza e caráter democrático (BOSI, 1994).

Inicialmente, em discussão sobre alguns elementos da luta das mulheres na história, observamos que um lugar significativo lhe foi negado durante muito tempo na historiografia. Assim, somente desde um processo de protestos e reivindicações de movimentos, como a "Segunda Onda" do movimento feminista, as mulheres conquistaram maior visibilidade histórica, constituindo subsídios para também a escrita de uma história das mulheres.

Tal reparação foi viabilizada pela viragem historiográfica que se deu especialmente com o surgimento da Escola dos Annales, a qual passou a contemplar temáticas antes excluídas pela história tradicional. Nesse contexto, a história das mulheres ganhou um espaço na historiografia.

Sobre os bailes axixaenses, estes eram festas que ocorriam tradicionalmente em Axixá, sem que houvesse preocupação com seu princípio, contudo, as lembranças e representações permaneceram. Eram festejos para homenagear alguns santos católicos, assim como o carnaval, possuindo agenda definida no calendário anual. Estes festejos receberam as denominações de "Baile de Primeira" e "Baile de Segunda", como forma de classificação, a partir de seus frequentadores(as). O" Baile de Primeira" era o frequentado pela camada social mais abastada da sociedade local, assim como pelas famílias ligadas a tais grupos, em uma relação de apadrinhamento. Estes bailes eram realizados geralmente em prédios públicos, com uma estrutura ofertada pelos grupos sociais de maior poder político e aquisitivo.

0 "Baile de Segunda" era visto com desprezo por boa parte das pessoas da cidade ditas "de bem", possuíam representação de lugares frequentados por "mulheres mal faladas", pelas "camaradas" (nome dado às amantes), pelos "briguentos" e "beberrões". Ocorriam em locais cedidos por pessoas da comunidade com alguma condição financeira, geralmente em arraiais cercados com a palha do babaçu.

A dinâmica de funcionamento desses bailes revelou a existência na sociedade axixaense de uma moral repressora instituída, definidora de posicionamentos sociais responsáveis pela 
manutenção das relações sociais da época, um projeto educativo em movimento. Um projeto que, em estudos como o de Oliveira (2017), intitulado "O único Deus na terra para uma mulher é o seu marido": a produção de códigos de gênero no Jornal "O Povo" e em processos-crimes do Seridó potiguar (1880-1900), explicita o viés extremista da representação da posição social feminina em diferentes sociedades. Verdadeiramente, os bailes funcionavam também como mecanismos de disciplinarização dos corpos, formadores de pessoas dóceis, disciplinadas, prontas para aceitar. Uma dinâmica educativa, especialmente no que se refere às mulheres, visto que estas tinham os seus papéis sociais e familiares estabelecidos, devendo aceitar as posturas insensíveis e de caráter vexatório dos seus maridos.

Sobre essa relação de dominação, dependência e consentimento, Chartier (2002a, p. 112) adverte sobre a existência da lógica da distinção pela dependência: "Pela etiqueta, a sociedade de corte procede à autorrepresentação, cada um distinguindo-se do outro, e distinguem-se todos em conjunto das pessoas estranhas ao grupo." Por conseguinte, o poder do disciplinamento das classes consideradas inferiores se constitui forma de atuação e reprodução social da parte dos setores dominantes, é claro, com o próprio consentimento dos(as) dominados(as), na medida em que nesse conjunto tanto se repelem quanto se atraem. Nesse direcionamento, dispositivos como os bailes excludentes presentes na sociedade de Axixá permaneceram "benfazejos", demarcando posições e sustentando a manutenção das relações sociais.

Elemento de forte ingerência na construção de um ideário social local é a religião. $\mathrm{Na}$ década de 1960, a população axixaense era majoritariamente católica, o que resultou na absorção da moral desse segmento religioso que se refletia nos usos e costumes de grande parte dessa população, embora houvesse aqueles que transgredissem tais normas morais. Logo, as diferenças sociais, assim como os estigmas relacionados à condição feminina, eram cimentados especialmente pela ação da Igreja Católica em Axixá. 0 poder moral católico na sociedade axixaense da década de 1960, como valor cultural, impregnava a maioria dos setores da sociedade, inclusive os ambientes festivos, embora houvesse um espaço que se desviava desse padrão moralizante, o "Baile de Segunda."

Aspecto digno de nota nesse processo ainda era o poder de escolha dos homens frequentadores do "Baile de Primeira", visto que a estes era permitida a participação nos dois bailes, mas quanto aos homens do "Baile de Segunda" permitia-se somente participar deste último, configurando clara discriminação social, que nos permitiu identificar uma distinção em relação aos outros homens. Circunstância que se explica, conforme Bourdieu (2007), pelo fato de os julgamentos e preferências estéticos estarem ligados à posição do indivíduo na sociedade, a um habitus de classe, visto que será a diferença entre os habitus de classe, entre os estilos de vida que estão na base da distinção entre as classes sociais, e que são analisados a partir das práticas culturais e de consumos culturais. Uma análise a explicitar toda violência simbólica, não perceptível como tal, inclusive pelas suas próprias vítimas envolvidas na luta de classe contemporânea que está por trás da reprodução social.

As mulheres, como mencionamos preliminarmente, estavam divididas em relação à participação nos espaços festivos. 0 "Baile de Primeira" era frequentado pelas mulheres casadas consideradas honradas e pelas moças solteiras de bom comportamento. Quanto ao "Baile de Segunda", tinha como frequentadoras as mulheres "mal faladas", solteiras com filhos em busca de casamento ou não.

A pesquisa nos possibilitou verificar que cada mulher atrelada ao seu respectivo baile constituía um significado universal pela sociedade axixaense daquela época, significado esse legitimado por cada grupo que construiu socialmente o "Baile de Primeira", o "Baile de 
Segunda" e o ideal de mulher que pudesse frequentá-los. Além disso, essa relação existente entre mulher e baile era considerada como exterior à sociedade, fazendo ocorrer o processo de internalização dos anseios de cada segmento social daquele momento.

Portanto, visto que o processo de diferenciação social se instaura, segundo Bourdieu (2007, 2012), no próprio gosto, constatamos que os bailes funcionavam, na sociedade axixaense da década de 1960, como mecanismos educativos na medida em que, pela sua dinâmica, realizavam um procedimento de inculcação social capaz de classificar indivíduos, notadamente as mulheres, que, por um processo silencioso e visto como "natural", tinham suas posições sociais e moral definidas naquela sociedade. Consequentemente, considerando as peculiaridades locais, as mulheres tinham como condição social predominante a de submissão, determinada a partir da difusão de uma falsa moral que lhes impunha um ideal de feminilidade, esperando-se delas que fossem sorridentes, simpáticas, atenciosas, submissas, discretas, contidas ou até mesmo apagadas. Uma condição/relação que terminava por se tornar parte de seu ser. Nesse sentido, concluímos que os bailes de "Primeira" e de "Segunda" em Axixá funcionavam como mecanismos/ lugares de um processo educativo, na medida em que realizavam a inculcação, especialmente dirigida às mulheres, de formas de ser e estar no mundo por meio de procedimentos sutis e legítimos socialmente.

\section{REFERÊNCIAS}

BAKHTIN, Mikhail, A cultura popular na Idade Média e no Renascimento: o contexto de François Rabelais. São Paulo: HUCITEC, 1993.

BOSI, Eclea. Memória e sociedade: Lembranças dos velhos. 3. ed. São Paulo: Companhia das Letras, 1994.

BOURDIEU, Pierre. A distinção: crítica social do julgamento. São Paulo: Edusp; Porto Alegre: Zouk, 2007.
BOURDIEU, Pierre. A dominação masculina. 11. ed. Rio de Janeiro: Bertran Brasil, 2012.

BRASIL. Presidência da República. Casa Civil. Lei no 11.340, de 07 de agosto de 2006. Cria mecanismos para coibir a violência doméstica e familiar contra a mulher, nos termos do $\S 8^{\circ}$ do art. 226 da Constituição Federal, da Convenção sobre a Eliminação de Todas as Formas de Discriminação contra as Mulheres e da Convenção Interamericana para Prevenir, Punir e Erradicar a Violência contra a Mulher; dispõe sobre a criação dos Juizados de Violência Doméstica e Familiar contra a Mulher; altera o Código de Processo Penal, o Código Penal e a Lei de Execução Penal; e dá outras providências. Brasília, DF, 2006. Disponível em: http://www. planalto.gov.br/ccivil_03/_Ato2004-2006/2006/ Lei/L11340.htm. Acesso em: 23 jul. 2021.

BRÜGGER, Silvia Maria Jardim. Minas patriarcal: família e sociedade (São João del-Rei - séculos XVIII e XIX). São Paulo: Annablume, 2007.

BURKE, Peter. A escrita da História: novas perspectivas. São Paulo: UNESP, 1992.

CAMPOS, Marize Helena de. Senhoras donas: economia, povoamento e vida material em terras maranhenses (1755-1822). São Luís: Café \& Lápis: FAPEMA, 2010.

CERTEAU, Michel de. A invenção do quotidiano: artes de fazer. Tradução Ephraim Ferreira Alves. 3. ed. Petrópolis, RJ: Vozes, 2008.

CHARTIER, Roger. A História cultural: entre práticas e representações. 2. ed. São Paulo: DIFEL, 2002a.

CHARTIER, Roger. A história ou a leitura do tempo. Belo Horizonte: Autêntica, 2010.

CHARTIER, Roger. 0 mundo como representação. In: CHARTIER, Roger. À beira da falésia: a história entre incertezas e inquietudes. Porto Alegre: UFRGS, 2002b. p. 61-80. Disponível em: http://www.scielo.br/scielo.php?pid=S0103$4014199100010001 \&$ script=sci_arttext. Acesso em: 23 set. 2020.

DEL PRIORE, Mary. História do amor no Brasil. São Paulo: Contexto, 2005.

FERREIRA, Marieta de Moraes. História oral: velhas questões, novos desafios. In: CARDOSO, Ciro Flamarion; VAINFAS, Ronaldo (org.). Domínios da História. Rio de Janeiro: Campus, 2011.p. 169-185. FLORENTINO, Manolo Garcia; GÓES, José Roberto. A paz das senzalas: famílias escravas e tráfico 
atlântico, Rio de Janeiro, 1790-1850. Rio de Janeiro: Civilização Brasileira, 1997.

FOUCAULT, Michel. Microfísica do poder. Rio de Janeiro: Graal, 2010.

FRANÇOIS, Etienne. A fecundidade da história oral. In: AMADO, Janaina; FERREIRA, Marieta de Moraes (org.). Usos e abusos da História oral. 8. ed. Rio de Janeiro: FGV, 2006. p. 3-13.

HALBWACHS, Maurice. A memória coletiva. 2. ed. São Paulo: Vértices, 1990.

HANNER, June E. Honra e distinção das famílias. In: PINSKY, Carla Bassanezi; PEDRO, Joana Maria (org.). Nova história das mulheres no Brasil. São Paulo: Contexto, 2013. p. 44-73.

OLIVEIRA, Marcos Fernandes de. "O único deus na terra para uma mulher é o seu marido": a produção de códigos de gênero no jornal "O Povo" e em processos-crimes do Seridó potiguar (1880-1900). 2017. 94 f. Dissertação (Mestrado em História) - Programa de Pós-Graduação em História, Universidade Federal de Campina Grande (UFCG), Campina Grande, PB, 2017. Disponível em: http://dspace.sti.ufcg.edu.br:8080/jspui/handle/ riufcg/1068. Acesso em: 21 fev. 2021.

PEREIRA, Cristiana Schettini. Os senhores da alegria: a presença das mulheres nas grandes sociedades carnavalescas cariocas em fins do século XIX. In: CUNHA, Maria Clementina Pereira da (org.). Carnavais e outras f(r)estas: ensaios de história social da cultura. Campinas, SP: Unicamp: CECULT, 2002. p. 311-332.

PINSKY, Carla Bassenezi. Gênero. In: PINSKY, Carla Bassanezi (org.). Novos temas nas aulas de Histó- ria. São Paulo: Contexto, 2010. p. 29-54.

PINTO, Céli Regina Jardim. Feminismo, História e poder. Revista de Sociologia e Política, Curitiba, v. 18, n. 36, p. 15-23, jun. 2010.

RAGO, Margareth. Trabalho feminino e sexualidade. In: DEL PRIORE, Mary (org.). História das mulheres no Brasil. São Paulo: Contexto, 2013. p. 578-607.

SANTOS, Maurício dos. A casa grega no século V a.C. 2010. Centro de Pesquisa da Antiguidade. Disponível em: http://cpantiguidade.wordpress. com/2010/08/17/a-casa-grega-do-v-a-c. Acesso em: 19 jul. 2020.

SIMMEL, Georg. Questões fundamentais de sociologia: indivíduo e sociedade. Rio de Janeiro: Zahar, 2006.

SOIHET, Rachel. A conquista do espaço público. In: PINSKY, Carla Bassanezi; PEDRO, Joana Maria (org.). Nova história das mulheres no Brasil. São Paulo: Contexto, 2013. p. 218-237.

SUTIL. Séfora Semíramis. Das virtudes ou infortúnios femininos: os ideais de conduta no Brasil oitocentista. Cadernos de História, Belo Horizonte, v. 21, n. 34, p. 122-143, 2020.

TILLY, Louise A. Gênero, História das Mulheres e História Social. Cadernos Pagu, Campinas, SP, n. 3, p. 28-62, 2007. Disponível em: https://periodicos. sbu.unicamp.br/ojs/index.php/cadpagu/article/ view/1722. Acesso em: 23 set. 2020.

Recebido em: 12/03/2021

Aprovado em: 12/08/2021

(cc) BY-NC Este é um artigo publicado em acesso aberto sob uma licença Creative Commons. 